\title{
Evaluation of the lower protein limit in the budding yeast Saccharomyces cerevisiae using TIPI-gTOW
}

Masataka Sasabe ${ }^{1}$, Sayumi Shintani ${ }^{2}$, Reiko Kintaka ${ }^{2}, K^{2}$ azunari Kaizu ${ }^{3}$, Koji makanae ${ }^{1}$ and Hisao Moriya ${ }^{1 *}$

\begin{abstract}
Background: Identifying permissible limits of intracellular parameters such as protein expression provides important information for examining robustness. In this study, we used the TEV protease-mediated induction of protein instability (TIPI) in combination with the genetic Tug-of-War (gTOW) to develop a method to measure the lower limit of protein level. We first tested the feasibility of this method using ADE2 as a marker and then analyzed some cell cycle regulators to reveal genetic interactions.

Results: Using TIPI-gTOW, we successfully constructed a strain in which GFP- ${ }^{\text {TDegF }}$ Ade2 was expressed at the lower limit, just sufficient to support cellular growth under the -Ade condition by accelerating degradation by TEV protease. We also succeeded in constructing a strain in which the minimal level of GFP- ${ }^{\text {TDegF }}$ Cdc20 was expressed by TIPI-gTOW. Using this strain, we studied genetic interactions between cell cycle regulators and CDC20, and the result was highly consistent with the previously identified interactions. Comparison of the experimental data with predictions of a mathematical model revealed some interactions that were not implemented into the current model.

Conclusions: TIPI-gTOW is useful for estimating changes in the lower limit of a protein under different conditions, such as different genetic backgrounds and environments. TIPI-gTOW is also useful for analyzing genetic interactions of essential genes whose deletion mutants cannot be obtained.
\end{abstract}

\section{Background}

Effective functioning of cellular systems requires optimal expression of individual proteins [1-3]. On the other hand, cellular systems are generally robust against changes in protein expression [4-6]. Identifying permissible limits of intracellular parameters such as protein expression provides important information for examining robustness [4-6].

We previously developed a method designated genetic Tug-Of-War (gTOW), by which we can measure the limit of overexpression of a target protein $[7,8]$. In gTOW, we clone a target gene with its native promoter into a $2 \mu$-based plasmid harboring leu2d. Under leucine-lacking (-Leu) conditions, the copy number of the plasmid reaches $>100$ copies because of the selection bias driven by leu $2 d$. If the target protein expression

\footnotetext{
* Correspondence: hisaom@cc.okayama-u.ac.jp

${ }^{1}$ Research Core for Interdisciplinary Sciences, Okayama University, Kita-ku, Okayama, Japan

Full list of author information is available at the end of the article
}

reaches the upper limit, i.e., essential cellular functions come to a halt when the level of protein exceeds a certain limit, the gene/plasmid copy number must decrease to below the upper limit. In gTOW, we thus increase the expression of a protein to a limit by increasing the copy number and then determine the upper limit by measuring the corresponding copy number of the gene. Using gTOW, we previously measured the copy number limits for overexpression of 30 cell cycle regulatory genes in the budding yeast Saccharomyces cerevisiae and studied the robustness of the cell cycle and mechanisms that can improve the robustness of the cell cycle $[7,9,10]$. We recently measured the copy number limits of all yeast genes and showed that the yeast cellular system is robust against $>100$-fold increase in the copy numbers of each of $>80 \%$ genes [11]. In that analysis, we also identified 115 "dosage-sensitive genes" whose copy number limits were $<10$ [11].

While gTOW is a method to measure the upper limit of protein expression, determination of the lower limit is

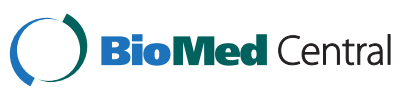


still a question. The commonly used gene-deletion experiments reduce the expression of a target protein to 0 . Gene-deletion experiments for all genes in S. cerevisiae have revealed that about $20 \%$ genes are essential for cellular growth under normal conditions [12]; other genes are essential for cellular growth under specific conditions such as specific environmental conditions or in combination with other gene knockouts [13,14]. Each of these proteins must have a minimal requirement level (i.e., the lower limit) to support cellular growth under each of these conditions. At present, there is no effective method to assess the lower expression limit of a target protein.

To assess the lower limit, we have to gradually reduce the expression of a protein and then measure the lower limit by some methods. To reduce the expression of a gene/protein, we need to reduce the production rate of the transcript, increase the degradation rate of the transcript, decrease the production rate of the protein, or increase the degradation rate of the protein. To identify the lower limit of expression, we would need to specifically decrease/increase the production/degradation rate of the target and evaluate the limit that would halt cellular function. Experimental methods that could potentially be used for this purpose in S. cerevisiae are as follows: (1) decreasing the expression rate of the transcript using a repressible promoter [15], (2) decreasing the transcription rate or increasing the degradation rate using RNA interference (RNAi) [16], (3) increasing the degradation of mRNA by the decreased abundance by mRNA perturbation (DAmP) method [17,18], (4) increasing the rate of degradation of the transcript by recruiting the RNA-degrading enzyme to the 3' region of the transcript [19], (5) increasing the rate of degradation of the protein using inducible degrons [20,21], (6) increasing the rate of degradation of the protein using the TEV protease-mediated induction of protein instability (TIPI) method [22,23].

In this study, we used TIPI in combination with gTOW to develop a method to measure the lower limit of protein expression. In TIPI, a target protein is expressed with a TEV protease-induced degron, an $\mathrm{N}$-terminal sequence containing a cleavage site for the site-specific TEV protease. Cleavage of the protein at this site by the TEV protease triggers the exposure of the "N-degron" [24], which triggers the rapid degradation of the target protein through the $\mathrm{N}$-end rule pathway. We chose TIPI because, theoretically, we can increase the degradation rate of the target protein by increasing the expression of TEV protease using the gTOW scheme with a plasmid encoding TEV. We can then evaluate the lower limit of the target protein expression by measuring the copy number of the TEV plasmid. We first tested the feasibility of this method using $A D E 2$ as a marker and then analyzed some cell cycle regulators to reveal genetic interactions.

\section{Results and discussion}

\section{Establishment of TIPI-gTOW using ADE2 as a marker}

In the gTOW method, we cloned the target gene into a plasmid and increased the copy number using the genetic bias for leu2d $[7,8]$. In this study, by increasing the copy number of the gene encoding TEV protease using the gTOW scheme, we attempted to increase the degradation rate of a target protein containing a TEV protease-induced degron (Figure 1). If the target protein expression is at the lower limit for any essential cellular function, the degradation rate must be less than that required to maintain the lower limit, which will restrict the upper limit copy number of the gene encoding TEV. We designated this scheme TIPI-gTOW.

To ensure the success of this approach, we need to adjust the expression of the following: (1) the target protein (determined by the production and degradation rate) to be in the range required to support the growth of the cell (not too high and not too low) and (2) the TEV protease to be in the appropriate range to induce degradation in order to detect the lower limit of the target protein expression. Taxis et al. used the $C Y C 1$ promoter and $A D H 1$ promoter to express target proteins and the GAL1 promoter to induce TEV protease expression $[22,23]$. In some cases, they could not observe expected lethal phenotypes, probably because the induced degradation of the target proteins by the TEV protease was insufficient to reduce the protein expression to their lower limits $[22,23]$.

We used constitutive promoters to increase the expression of TEV protease in accordance with the increase in gene copy number. We first used the $S$. cerevisiae TEF1 promoter to express TEV protease, but the strong expression of TEV protease from the TEF1 promoter on the high-copy gTOW plasmid in itself caused a cellular growth defect (data not shown). We currently do no know what causes this toxicity. We then used the CUP1 promoter. In the culture conditions we used $\left(0.25 \mu \mathrm{M} \mathrm{Cu}^{2+}\right)$, the CUP1 mRNA level was about $10 \%$ of the TEF1 mRNA level (data not shown). Expression of the TEV protease from the CUP1 promoter did not show any cellular growth defect, even when the gene copy number exceeded 100 (data not shown). We used an efficient version of the p14-TEV fusion protein $\left(\mathrm{p} 14 *-\mathrm{TEV}^{+}\right)[22,23]$; here, we designated this "pTEV ${ }^{+}$." We also designated the gTOW plasmid encoding the $\mathrm{pTEV}^{+}$expressed from the CUP1 promoter as the "TEV plasmid."

To test the feasibility of TIPI-gTOW, we selected $A D E 2$ as a target. $A D E 2$ encode phosphoribosylaminoimidazole carboxylase, an enzyme involved in the adenine 


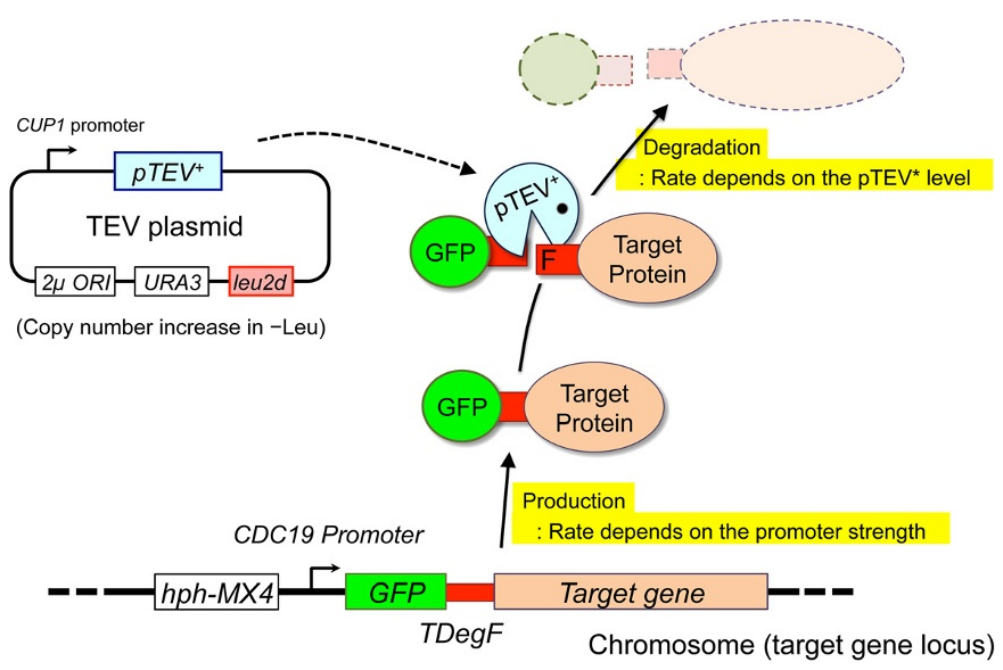

Figure 1 Scheme of TIPI-gTOW. We first constructed a strain in which the chromosomal target gene was replaced by a GFP- ${ }^{\text {TDegF }}$ target $^{\text {I }}$ construct. We next introduced the TEV plasmid, a plasmid for gTOW that encodes pTEV ${ }^{+}$expressed from the CUP1 promoter. According to the TIPI procedure, cleavage and rapid degradation of the GFP- ${ }^{\text {TDegF }}$ target is induced by PTEV ${ }^{+}$. Using the gTOW procedure, in which the copy number of the TEV plasmid exceeds 100 under the -Leu condition, we can increase the expression of pTEV $^{+}$, which accelerates the degradation of the GFP- ${ }^{\text {TDegF }}$ target, reducing the level of the GFP- ${ }^{\text {TDegF }}$ target. It is thus expected that the upper limit copy number of the TEV plasmid would inversely correlate with the lower limit of the GFP- ${ }^{{ }^{D} \text { egF }}$ target. The tug-of-war between the bias to increase the copy number of leu2d and the bias to decrease the copy number of pTEV ${ }^{+}$gene determines the plasmid copy number in the cell under the -Leu condition. It is thus possible to indirectly estimate the lower limit of the GFP- ${ }^{\text {TDegF }}$ target by measuring the copy number of the TEV plasmid.

synthesis. Reduction of Ade2 protein can be indirectly monitored by assessing cellular growth defect and by accumulation of red pigment in the absence of adenine [25]. We integrated $A D E 2$ with the TEV-induced degron expressed from the $C D C 19$ promoter into the chromosomal ADE2 locus (Figure 1). We chose the TDegF degron because it is one of the strongest degrons $[22,23]$. We then introduced the TEV plasmid into the cell. The results of TIPI-gTOW experiments of $A D E 2$ are shown in Figure 2. Cellular growth deficiency and red colony formation were observed for cells containing the TEV plasmid in the -Leu-Ade condition (Figure 2A). We note that colonies are expected to be redder on $\mathrm{SC}-$ Ura-Leu plates than the ones on SC-Ura plates, but they were not (Figure 2A). We currently do not know the reason. Unknown interaction between the leucine deficiency and the red color formation might exist. We next measured the copy numbers of the TEV plasmid and found that the copy number limit of the TEV plasmid decreased significantly under the -Leu-Ade condition (Figure 2B). We thus ensured that the Ade2 protein was expressed at the lower limit and indirectly estimated the lower limit from the TEV plasmid copy number. We note that the copy numbers of the vector were significantly different in between -Ura-Leu and -Ura-Leu-Ade conditions $(\mathrm{p}<0.01$, Student's $t$-test). The replication and/ or partition of the $2 \mu$-based plasmid might be affected by the growth conditions.

\section{TIPI-gTOW experiments of cell cycle regulators}

We next selected 3 essential cell cycle regulators as target genes to test if TIPI-gTOW was a feasible approach to assess their lower limits. We constructed the GFPTDegF constructs for $C D C 15, C D C 20$, and $C D C 28$ and integrated these into their chromosomal loci. At first, we used the full-length $C D C 19$ promoter (729 bp) to express the cell cycle proteins but could not obtain a $C D C 20$ construct, probably because strong expression of $C D C 20$ is toxic [26]. We then constructed a series of deletions of the $C D C 19$ promoter to reduce its expression (Additional file 1: Figure S1). The GFP expression from promoters with a length of $500 \mathrm{bp}$ or less was markedly lower than that from promoters exceeding 500 bp (Additional file 1: Figures S1B and S1C). This reduction might be due to the deletion of a Tye7 binding site located at -523 bp to -516 bp (Additional file 1: Figure S1A). We thus used the full-length $C D C 19$ promoter (729 bp), the $C D C 19_{-600}$ promoter (600 bp), and the CDC19-500 promoter (500 bp) to construct the GFP-TDegF target.

The results of the constructions are summarized in Additional file 1: Table S1. GFP- ${ }^{T D e g F} C D C 15$ constructs with all 3 promoters were obtained. We observed reduction in the copy number of the TEV plasmid with the ${ }_{C D C 19-500}$ promoter construct, but this was not significant (Figure 3A, $p>0.01$, Student's $t$-test). The lower limit of Cdc15 may be lower than that produced by TIPI-gTOW. As described above, we could not obtain a $G F P^{-T D e g F} C D C 20$ construct with the full-length $C D C 19$ 


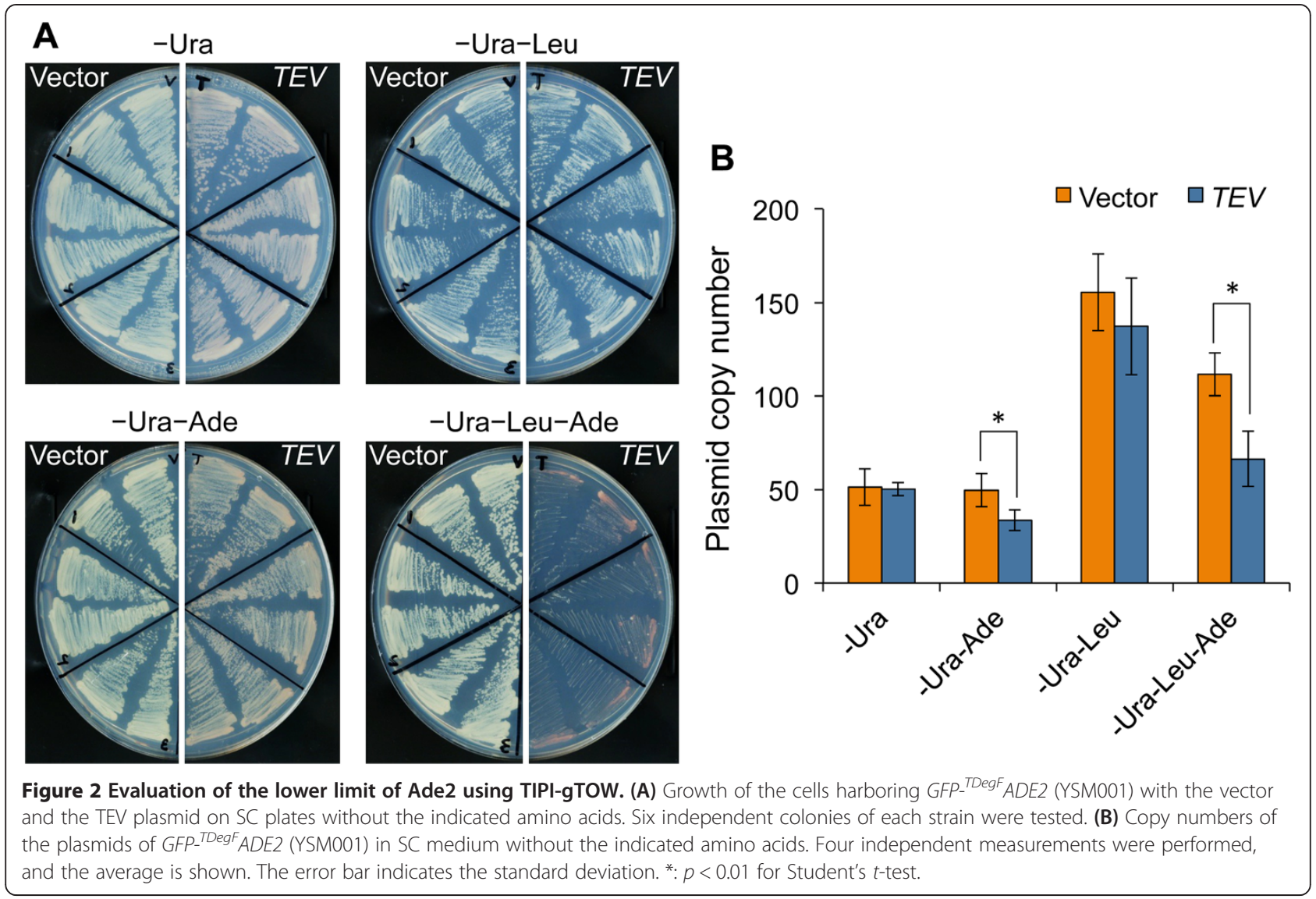

promoter or the $C D C 19_{-600}$ promoter probably because the expression was too high. However, we obtained a GFP- ${ }^{T D e g F} C D C 20$ integrated strain with the $C D C 19_{-500}$ promoter. With this strain, we succeeded to detect significant restriction of the copy numbers of the TEV plasmid under both -Ura and -Ura-Leu conditions (Figure 3B, $p<0.01$, Student's $t$-test). We obtained GFP${ }^{\text {TDegF }}$ CDC28 integrated strains with all the 3 promoters and observed significant restrictions of the copy number of the TEV plasmid with the CDC19-60o promoter under the - Ura - Leu condition (Figure 3C, $p<0.01$, Student's $t$-test). We did obtain a GFP- ${ }^{T D e g F} C D C 28$ integrated strain with the $C D C 19_{-500}$ promoter but could not obtain any transformants with the TEV plasmid, probably because the expression of $\mathrm{Cdc} 28$ from the $C D C 19_{-500}$ promoter was already close to the lower limit of $\mathrm{Cdc} 28$, even in the absence of TEV protease.

Reduction in the protein expression of GFP- ${ }^{\mathrm{TDegF}} \mathrm{Cdc} 28$ by TEV protease was confirmed by western blotting with anti-GFP antibody (Figure 3D). The GFP- ${ }^{\text {TDegF }} \mathrm{Cdc} 28$ protein expressed from the CDC19-500 promoter seemed to be too low to be detected by western blotting (Figure 3D). Simultaneously, we could not detect any GFP- ${ }^{\text {TDegF }}{ }^{2}$ dc20 protein expressed from the CDC19-500 promoter (data not shown).
We further analyzed the TEV protease dependent cleavage and reduction of GFP- ${ }^{\mathrm{TDegF}} \mathrm{Cdc} 28$ by western blotting with anti-Cdc28 antibody (Figure 3E). The protein levels of GFP- ${ }^{\mathrm{TDegF}}{ }^{\mathrm{Cdc} 28}$ in YSM005 ( $P_{-} C D C$ 19 -600-GFP- $\left.^{\text {TDegF }} C D C 28\right)$ were highly reduced in the presence of the TEV plasmid compared with the vector control, and the level was lower under the -Ura-Leu condition, where the expression of $\mathrm{pTEV}^{+}$increased, than the -Ura condition. Cleaved products ( $\left.{ }^{\mathrm{degF}} \mathrm{Cdc} 28\right)$ were also observed in the presence of the TEV plasmid. The summed levels of the GFP- ${ }^{\text {TDegF }}{ }^{2 d c} 28$ and ${ }^{\mathrm{degF}} \mathrm{Cdc} 28$ were comparable with the Cdc28 levels expressed in BY4741 (wild type). These results confirmed that the target protein level was actually reduced using TIPI-gTOW. We also tired to detect Cdc20 by western blotting using anti-Cdc20 antibodies (sc-6730 and sc-6731, Santa Cruz biotechnology). However, we could not detect any signal, probably because the expression level of $\mathrm{Cdc} 20$ is too low to detect with these antibodies.

\section{Estimation of changes in the lower limit of $C D C 20$ in gene-deletion strains}

As described above, we identified conditions under which the GFP- ${ }^{\mathrm{TDegF}} \mathrm{Cdc} 20$ expression was reduced to 


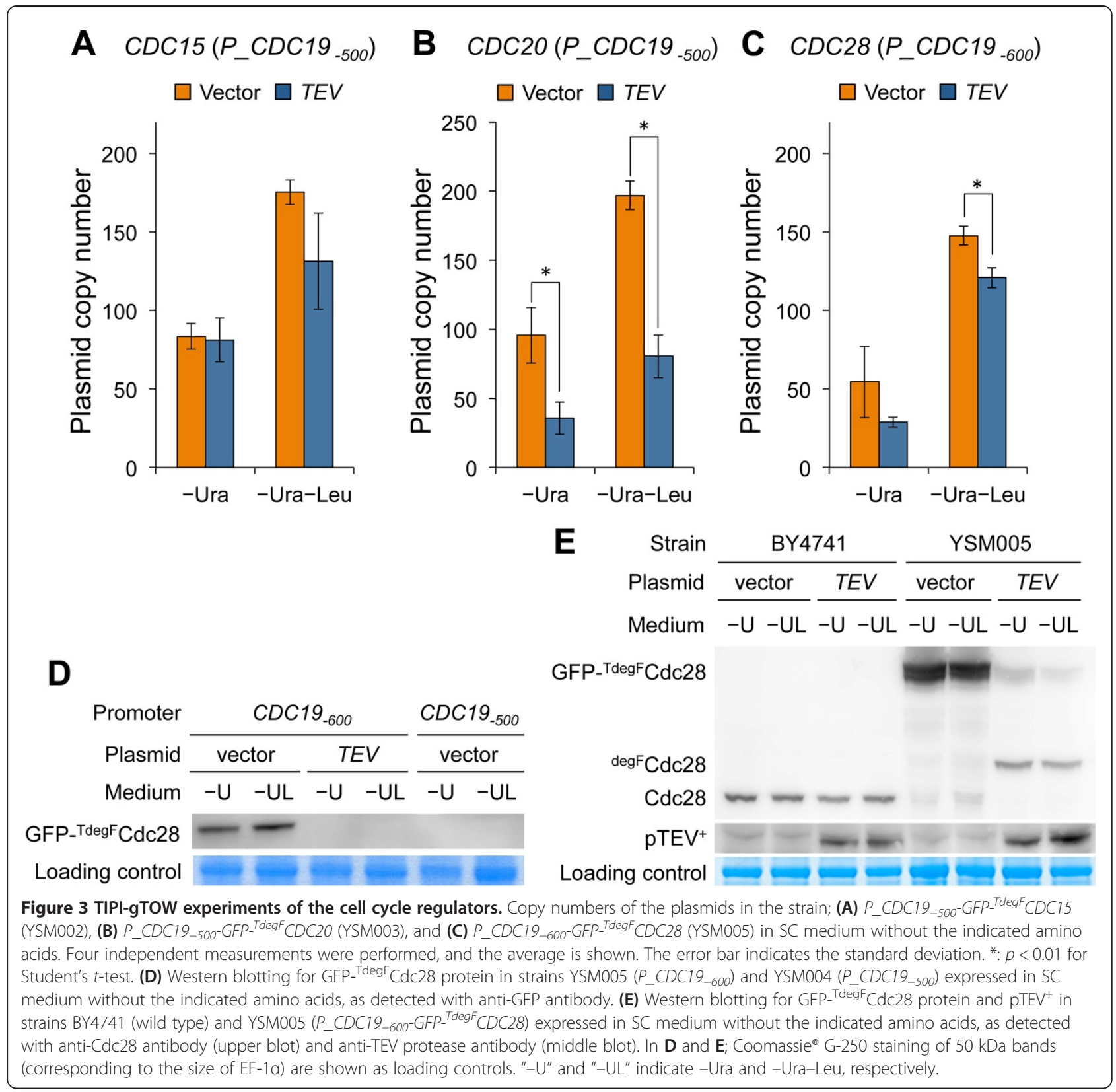

the lower limit. We next tried to estimate the lower limits of $\mathrm{GFP}_{-}{ }^{\mathrm{T} \text { eg }}{ }^{\mathrm{Cdc}} 20$ in gene-deletion strains using TIPI-gTOW. We integrated the P_CDC19 ${ }_{-500}-G F P-$ ${ }^{T D e g F} C d c 20$ construct into the chromosomal $C D C 20$ locus of each of 23 cell cycle regulator deletion strains and measured the TEV plasmid copy number. The copy number data is shown in Table 1 . We first noticed that the copy numbers of the vector itself varied among deletion strains. This may be because of differences in the growth rate or the efficiency of replication and partitioning of the plasmid among the deletion strains.

In addition, we observed significant correlations in the copy numbers of the vector and the TEV plasmid under both -Ura $(r=0.61)$ and -Ura-Leu $(r=7.0)$ conditions (Additional file 1: Figure S2). We thus considered that it was not appropriate to simply estimate the lower limit of GFP- ${ }^{\text {TDegF }}{ }^{2}$ dc20 from the copy number of the TEV plasmid in each deletion strain. Therefore, we calculated the ratio of the copy number of the TEV plasmid to that of the vector in each deletion strain and compared the ratio with that of the wild type to estimate the relative change in TEV plasmid copy number (see Methods for details).

Figure 4A and Table 1 show the relative copy number change in each deletion strain. Some strains, such as $\operatorname{cln} 1 \Delta$, sic1 $1 \Delta$, and $c d h 1 \Delta$, had negative relative copy number change values, which indicated that the copy 
Table 1 Copy numbers of the vector and the TEV plasmid in CDC20 TIPI-gTOW in the gene-deletion strains

\begin{tabular}{|c|c|c|c|c|c|c|}
\hline & Vector co & & TEV plasn & ber* & TEV/ & Relative change \\
\hline & Average & SD & Average & SD & & \\
\hline Wild type & 149.7 & 43.4 & 59.8 & 19.9 & 0.40 & - \\
\hline bck2 $2 \triangle$ & 44.3 & 3.4 & 25.3 & 0.8 & 0.57 & 0.43 \\
\hline bub2d & 71.4 & 8.4 & 48.6 & 3.5 & 0.68 & 0.70 \\
\hline cdh1A & 66.7 & 5.7 & 19.6 & 2.2 & 0.29 & -0.27 \\
\hline $\operatorname{cin} 84$ & 53.7 & 20.0 & 37.1 & 5.0 & 0.69 & 0.73 \\
\hline clb14 & 57.6 & 5.2 & 19.2 & 2.2 & 0.33 & -0.16 \\
\hline$c 1 b 24$ & 56.3 & 4.3 & 20.2 & 7.8 & 0.36 & -0.10 \\
\hline clb34 & 77.5 & 15.1 & 27.7 & 3.6 & 0.36 & -0.11 \\
\hline clb44 & 59.4 & 4.5 & 19.3 & 2.1 & 0.32 & -0.19 \\
\hline clb54 & 98.0 & 21.4 & 33.6 & 6.5 & 0.34 & -0.14 \\
\hline clb64 & 76.1 & 8.6 & 31.6 & 2.7 & 0.42 & 0.04 \\
\hline $\operatorname{cln} 14$ & 80.1 & 24.3 & 20.7 & 0.6 & 0.26 & -0.35 \\
\hline $\operatorname{cln} 2 \Delta$ & 82.7 & 15.8 & 42.9 & 3.8 & 0.52 & 0.30 \\
\hline $\operatorname{cln} 34$ & 47.0 & 10.9 & 22.0 & 10.8 & 0.47 & 0.17 \\
\hline Iteld & 84.8 & 20.9 & 32.0 & 16.0 & 0.38 & -0.06 \\
\hline $\operatorname{mad} 2 \Delta$ & 47.4 & 6.0 & 35.2 & 2.9 & 0.74 & 0.86 \\
\hline mbp14 & 21.6 & 11.4 & 15.0 & 2.1 & 0.69 & 0.73 \\
\hline $\operatorname{mih1} 1 \Delta$ & 64.4 & 12.1 & 29.3 & 3.7 & 0.46 & 0.14 \\
\hline $\operatorname{sic} 14$ & 71.8 & 20.1 & 20.2 & 11.8 & 0.28 & -0.29 \\
\hline sweld & 124.4 & 13.0 & 42.2 & 5.3 & 0.34 & -0.15 \\
\hline swi4d & 76.1 & 15.1 & 28.4 & 6.6 & 0.37 & -0.07 \\
\hline swi54 & 94.0 & 23.8 & 37.3 & 12.6 & 0.40 & -0.01 \\
\hline swi64 & 64.0 & 8.7 & 35.2 & 7.2 & 0.55 & 0.38 \\
\hline whi54 & 69.6 & 15.8 & 33.8 & 10.9 & 0.49 & 0.22 \\
\hline
\end{tabular}

${ }^{*}$ Average and SD of four independent experimental trials are shown.

numbers of the TEV plasmids in these strains were lower than those in the wild type, indicating that the lower limits of GFP- ${ }^{\mathrm{TDegF}} \mathrm{Cdc} 20$ increased in these strains. This implies that the deleted genes are involved in the production or activation of $\mathrm{Cdc} 20$ or have functions overlapping those of Cdc20 (Additional file 1: Figure S3). In these cases, the genes could be synthetically lethal with $c d c 20$ mutants or multicopy suppressors of $c d c 20$ mutants.

Other strains, such as $\operatorname{mad} 2 \Delta$, $\operatorname{cin} 8 \Delta$, and $\operatorname{mbp} 1 \Delta$, showed positive relative copy number change values, indicating that the copy numbers of the TEV plasmids were higher than those in the wild type; thus, the lower limits of GFP- ${ }^{\mathrm{TDegF}} \mathrm{Cdc} 20$ decreased in these strains. These deleted genes are therefore involved in inhibition of Cdc20, e.g., by inhibition of Cdc20 production or Cdc20 activity or degradation of Cdc20 (Additional file 1: Figure S4). These genes could be dosage suppressors of the toxicity of Cdc20 overexpression.

Previous studies, including systematic analyses, identified genes showing genetic interactions with $C D C 20$
[13,27-30]; these were listed in the Saccharomyces Genome Database (yeastgenome.org). From these interactions, we summarized relevant genetic interactions studied here in Table 2 and Figure 4A. Importantly, the relative copy number of the TEV plasmid decreased in deletion strains involving genes showing synthetic lethality or dosage rescue of the $c d c 20$ mutant, whereas the relative copy number of the TEV plasmid increased in deletion strains involving genes showing synthetic rescue, phenotypic suppression, and dosage lethality of the $c d c 20$ mutant. This result indicated that our TIPIgTOW approach gave information regarding genetic interactions, which was highly consistent with the previously identified interactions. Moreover, the advantage of our approach is that we could isolate genetic interactions in both directions, namely negative interactions such as synthetic lethal and dosage rescue and positive interactions such as synthetic rescue, phenotypic suppression, and dosage lethality in a single experiment.

Among genetic interactions obtained in this study, the difference between CLN1 and CLN2 was surprising 


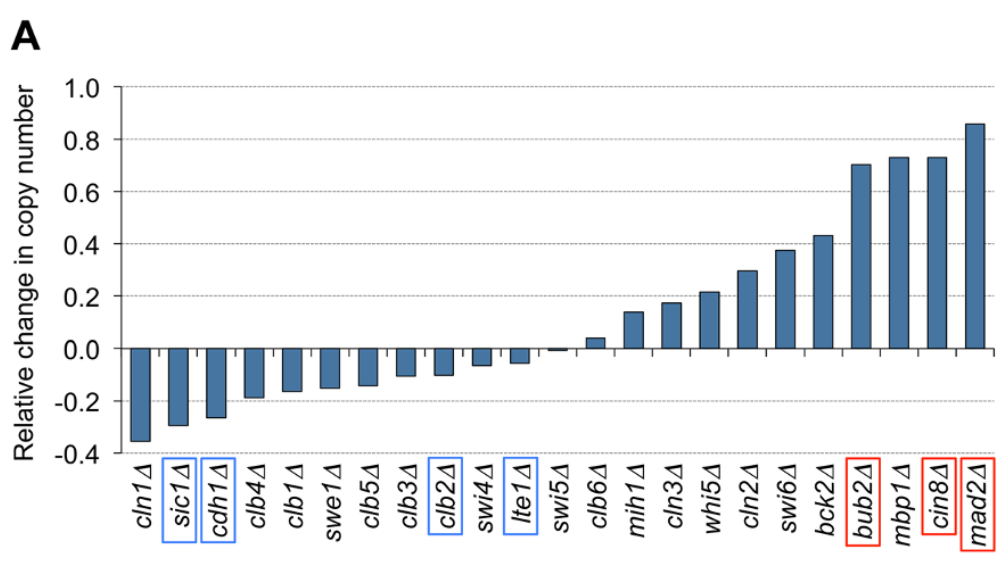

$\square$ Synthetic lethal, Dosage rescue

Synthetic rescue, Phenotypic suppression, Dosage lethality

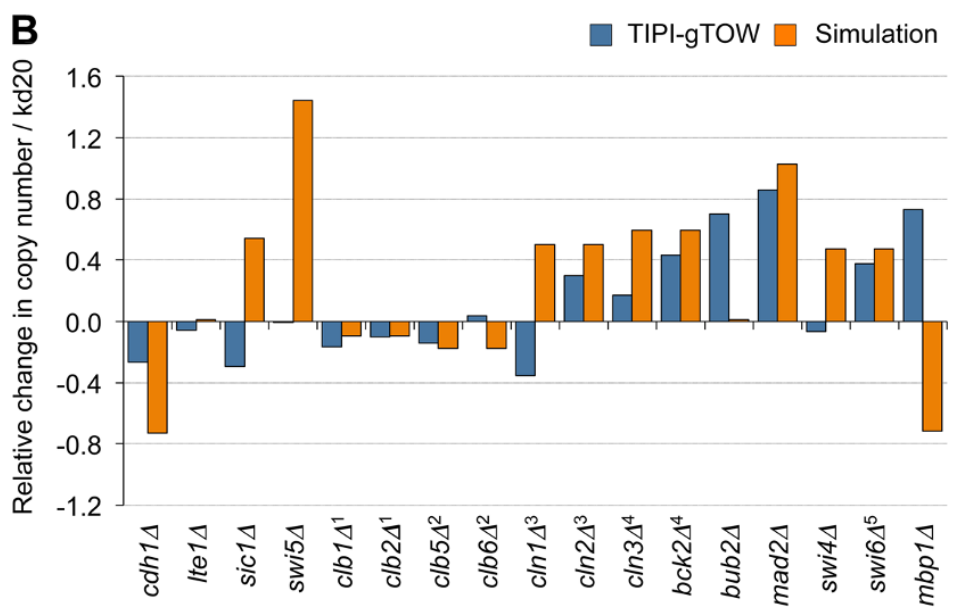

Figure 4 Evaluation of the lower limits of Cdc20 protein on deletion of cell cycle regulators. (A) Relative copy number changes in the TEV plasmids in gene-deletion strains with GFP- ${ }^{\text {TdegF }}$ CDC20. Genes with previously identified genetic interactions with cdc20 mutation were boxed (summarized in Table 2). The original data used for the graph is shown in Table 1. (B) Relative copy number changes in TEV plasmids in genedeletion strains with GFP- ${ }^{\text {TdegF }} C D C 20$ selected from $\mathbf{A}$ and simulation results. The degradation rate of $\mathrm{kd} 20$ is gradually increased until the cell cycle simulation indicates "dead." In the simulation, 1: Clb1 and Clb2, 2: Clb5 and Clb6, 3: Cln1 and Cln2, and 4: Cln3 and Bck2 are implemented as single genes. 5: Swi6 is implemented into the component of SBF (together with Swi4) and MBF (together with Mbp1). The original data used for the graph is shown in Table 1 and Additional file 1: Table S2.

Table 2 Known genetic interactions with CDC20 mutation listed in the Saccharomyces Genome Database*

\begin{tabular}{|c|c|c|c|}
\hline Gene & Genetic interaction with the $c d c 20$ Mutant & Description & References \\
\hline$\overline{B \cup B 2}$ & Synthetic Rescue & Temperature sensitivity of $c d c 20-1$ (ts) is rescued by bub2 deletion. & [27] \\
\hline $\mathrm{CDH} 1$ & Synthetic Lethality & $c d c 20-1$ (ts) shows synthetic lethality with $c d h 1$ deletion. & {$[28]$} \\
\hline CIN8 & Dosage Lethality & In the absence of $C I N 8$, overexpression of $C D C 20$ is lethal. & [29] \\
\hline CLB2 & Negative Genetic & Growth defect of cdc20_tsq368 increases with clb2 deletion. & [13] \\
\hline LTE1 & Synthetic Lethality & cdc20-1(ts) shows synthetic lethality with Itel deletion. & [28] \\
\hline MAD2 & Phenotypic Suppression & cdc20 blocks the premature degradation of Pds 1 observed in a mad2 mutant. & [30] \\
\hline$S I C 1$ & Synthetic Lethality & cdc20-1(ts) shows synthetic lethality with sic1 deletion. & [28] \\
\hline
\end{tabular}

*When synonymous genetic interactions were reported in more than one study, one representative is listed. 
because they are known to have heavily overlapped functions [31]. Previous analysis, however, showed that CLB4 has opposite genetic interactions with CLN1 and CLN2 [32]. Our results might indicate that these genes have different functions in some contexts.

Comparison of experimental data with predictions of a simulation model is useful for evaluating the predictive ability of the mathematical model and for speculating about molecular mechanisms generating negative/positive genetic interactions $[7,9,10]$. An integrative mathematical model of the budding yeast cell cycle was developed previously [33], and we have modified this model using gTOW data [9]. Using the "stabilization model" published in the reference [9], we here measured how much the degradation parameter of Cdc20 could be increased (i.e., the upper limit of $\mathrm{kd} 20$ ) in each of the gene-deletion models and compared the upper limit of $\mathrm{kd} 20$ with that in the wild type to obtain the relative change in the upper limit of kd20 (see Methods for details). This analysis is considered to represent the process of TIPI-gTOW, namely indirectly assessing the lower limits of Cdc20 in the presence of gene deletions, by measuring how much degradation can increase without halting the cell cycle. The simulation result is shown in Additional file 1: Table S2. Figure 4B shows the comparison of the results of TIPI-gTOW and those of the simulation. Deletion strains, such as $\operatorname{mad} 2 \Delta, \operatorname{cdh} 1 \Delta$, and others, showed good agreements between TIPI-gTOW and simulation data; however, some genes such as sic1 $\Delta$, swi5 $\Delta$, and mbp1 $1 \Delta$ showed almost opposite changes, suggesting absence of some regulatory steps in the model.

\section{Conclusions}

In this study, we tried to develop a method for estimating the lower limit of protein expression by combining the TIPI and gTOW methods. Using TIPI-gTOW, we successfully constructed a strain in which GFP- ${ }^{\text {TDegF }}$ Ade2 was expressed at the lower limit, just sufficient to support cellular growth under the -Ade condition by accelerating degradation by TEV protease.

We also succeeded in constructing a strain in which the minimal level of GFP- ${ }^{\mathrm{TDegF}} \mathrm{Cdc} 20$ was expressed by TIPI-gTOW. Using this strain, we studied genetic interactions between cell cycle regulators and CDC20. We concluded that TIPI-gTOW is useful for estimating changes in the lower limit of a protein under different conditions, such as different genetic backgrounds and environments. TIPI-gTOW is useful for analyzing genetic interactions of essential genes whose deletion mutants cannot be obtained. One important characteristic of TIPI-gTOW is that it is useful for identifying both negative and positive genetic interactions, as shown in Figure 4. The synthetic genetic array is a potent highthroughput approach to identifying genetic interactions
[34], which now allows quantitative analyses [35] and can also applied to essential genes [36]. TIPI-gTOW developed in this study may be an alternative method to study genetic interactions in detail.

The conventional gTOW method developed previously uses a gene with a native promoter and terminator as a unit to increase protein expression and measures the copy number limit to estimate the "copy number limit for protein overexpression" $[7,8,10,11]$. The advantage of gTOW is that we can indirectly estimate by how much a target protein can be overexpressed over the native level by simply measuring the copy number of the gTOW plasmid. In TIPI-gTOW, however, we first have to modify the native copy of the target gene, which changes the native expression, activity, and stability of the target protein. In addition, the aim of the procedure is to reduce the expression of the target protein, which makes it difficult to quantitate the lower limit of the target protein by western blotting when this level is under the detection limit. In fact, we have failed to detect the protein levels of Ade 2 and Cdc20 by western blotting using their specific antibodies (data not shown). We thus believe that TIPI-gTOW is a method by which a cellular condition can be constructed with the target protein expressed at the lower limit still supporting cellular function. Thus, it is useful for identifying genetic interactions as described above, although it does not measure the absolute lower limit of the target protein.

To use TIPI-gTOW, the optimal expression for the target GFP-TDegF protein must be determined so that the level is within the range of detection of the lower limit by increasing the TEV plasmid. Taxis and Knop developed a series of TDeg constructs with different promoters and N-degrons of various strengths [23], which will be useful to systematically determine the optimal expression.

Previous studies on haploinsufficiency and dosage compensation suggested that most of yeast proteins are expressed at least twice more than the levels required in diploid cells $[37,38]$. If we could detect the lower limit protein levels under the TIPI-gTOW experiments, we might be able to argue about this issue. We failed to detect some proteins using western blotting with specific antibodies as described above. Fusing the target proteins with more sensitive proves might be useful.

\section{Methods}

\section{Yeast strains and growth conditions}

Yeast strains used in this study are listed in Table 3. A S. cerevisiae strain BY4741 (MATa, his $3 \Delta 1$, leu2 $\Delta 0$, met15 $\Delta 0$, ura3 $\Delta 0$ ) [39] was used as the host strain for the experiments. BY4741 derivatives with gene deletions in the cell cycle regulators were obtained from Open Biosystems/Thermo Scientific. YSM001 was constructed 
Table 3 Yeast strains used in this study

\begin{tabular}{|c|c|c|}
\hline Name & Genotype & Source \\
\hline BY4741 & MATa, his3 $\Delta 1$, leu2 $\Delta 0$, met15 140 , ura3 $\Delta 0$ & [39] \\
\hline YSM001 & $\begin{array}{l}\text { ade2::hphMX-P_CDC19-GFP- }{ }^{\text {TDegF }} \\
\text { ADE2 in BY4741 }\end{array}$ & This study \\
\hline YSM002 & $\begin{array}{l}\text { cdc15::hphMX-P_CDC19-500-GFP_tDegF } \\
\text { CDC15 in BY4741 }\end{array}$ & This study \\
\hline YSM003 & $\begin{array}{l}\text { cdc20::hphMX-P_CDC19-500-GFP_DegF } \\
\text { CDC20 in BY4741 }\end{array}$ & This study \\
\hline YSM004 & $\begin{array}{l}\text { cdc28::hphMX-P_CDC19-500-GFP_- }{ }_{-}^{\text {TDegF }} \\
\text { CDC28 in BY4741 }\end{array}$ & This study \\
\hline YSM005 & $\begin{array}{l}\text { cdc28::hphMX-P_CDC19-60-GFP_DegF } \\
\text { CDC28 in BY4741 }\end{array}$ & This study \\
\hline
\end{tabular}

by integrating the $P_{-} C D C 19-G F P_{-}{ }^{T D e g F} A D E 2$ fragment, which was amplified by PCR with the primers OHML432 and OHML389 using pSS1002 as a template, into the chromosomal ADE2 locus of BY4741. Similarly, YSM002 was constructed by integrating the $P_{-} C D C 19_{-500^{-}}$ $G F P_{-}{ }^{T D e g F}$ fragment, which was amplified by PCR with the primers OHML504 and OHML505 using pSM001 as a template, into the chromosomal CDC15 locus of BY4741. YSM003 was constructed by integrating the P_CDC19-500-GFP- ${ }_{-}^{\text {TDegF }}$ fragment, which was amplified by PCR with the primers OHML506 and OHML507 using pSM001 as a template, into the chromosomal CDC20 locus of BY4741. YSM004 was constructed by integrating the $P_{-} C D C 19_{-500^{-G F P}-{ }^{T D e g F}}$ fragment, amplified by PCR using the primers OHML508 and OHML509 and pSM001 as a template, into the chromosomal $C D C 28$ locus of BY4741. YSM005 was constructed as for YSM004, except that pSM002 was used as a PCR template. Each $P_{-} C D C 19_{-500^{-G F P-}{ }_{-}{ }^{T D e g F} C D C 20}$ integrated strain harboring a gene deletion was constructed by integrating the same DNA fragment as YSM003 into the chromosomal $C D C 20$ locus of each deletion strain. The sequences of PCR primers are listed in Additional file 1: Table S3. Yeast cells were cultured as described previously $[9,40]$. Yeast cells were cultured in SC media without uracil (Ura), adenine (Ade), leucine (Leu), and histidine (His) as indicated. $2 \%$ glucose was used as a carbon source. SC media were made using YNB with ammonium sulfate (MP biomedicals) that contains $0.25 \mu \mathrm{M} \mathrm{Cu}^{2+}$.

\section{Plasmids used in this study}

Plasmids used in this study are listed in Table 4. pSS1006 (the TEV plasmid) was constructed by inserting p14"$\mathrm{TEV}^{+}$from pDS5 [22] into pSBI40 [7] so that $\mathrm{p} 14^{\prime \prime}-\mathrm{TEV}^{+}$ is expressed under control of the CUP1 promoter. pSS1002 was constructed by connecting $h p h-M X 4$, a hygromycin B-resistance cassette [41], the $C D C 19$ promoter, GFP$T D e g F$ from pDS41 [22], and ADE2, followed by insertion into pRS423ks [11]. pSS1002, with different lengths of $C D C 19$ promoters, was constructed using the PCR primers
Table 4 Plasmids used in this study

\begin{tabular}{|c|c|c|}
\hline Name & Relevant characteristics & Source \\
\hline$\overline{p S B \mid 40}$ & $\begin{array}{l}2 \mu \text { ori, URA3, leu2d; plasmid } \\
\text { for gTOW experiment }\end{array}$ & [7] \\
\hline pRS423ks & $2 \mu$ ori, HIS3 & {$[11]$} \\
\hline pDS5 & p14*-TEV ${ }^{+}$ & {$[22]$} \\
\hline pDS41 & GFP-TDegF-SF3b & {$[22]$} \\
\hline pSS1002 & $\begin{array}{l}\text { hph-MX4, P_CDC19-GFP TDegF } \\
\text { ADE2 in pRS423ks }\end{array}$ & This study \\
\hline pSS1006 & P_CUP1-P14*-TEV ${ }^{+}$in pSBI40 & This study \\
\hline pSM001 & $\begin{array}{l}P_{-} C D C 19_{-500} \text { instead of } P_{-} C D C 19 \\
\text { in pSS1002 }\end{array}$ & This study \\
\hline pSM002 & $\begin{array}{l}P_{-} C D C 19_{-600} \text { instead of } P_{-} C D C 19 \\
\text { in } \mathrm{pSS} 1002\end{array}$ & This study \\
\hline
\end{tabular}

OHML541-547 and OHML540; the sequences are listed in Additional file 1: Table S3.

\section{Copy number determination of plasmids}

The copy number of a plasmid in a cell was measured as described previously [7] with some modifications. Cells of each yeast strain with pSS1006 (the TEV plasmid) or pSBI40 (the empty vector plasmid) were grown for $50 \mathrm{~h}$ in $200 \mu \mathrm{L} \mathrm{SC}$ medium without relevant amino acids. The cells were corrected and suspended into $50 \mu \mathrm{L}$ of Zymolyase solution (10 mM Na-phosphate [pH 7.5], $1.2 \mathrm{M}$ sorbitol, and $2.5 \mathrm{mg} / \mathrm{ml}$ Zymolyase $100 \mathrm{~T}$ (Nacalai tesque)). The cell suspension was incubated for $15 \mathrm{~min}$ at $37^{\circ} \mathrm{C}$, and then incubated for $10 \mathrm{~min}$ at $100^{\circ} \mathrm{C}$. After removing the cell debris by centrifugation, the supernatant was used as the total DNA solution. Two real-time PCRs were performed using $2 \mu \mathrm{L}$ of the DNA solution as templates with $L E U 2$ and $L E U 3$ primer sets (primer sequences are listed in Additional file 1: Table S3), using LightCycler ${ }^{\circ}$ 480 SYBR Green I Master with the LightCycler 480 system (Roche). The LEU2 and LEU3 primer sets were used to quantify the LEU2 DNA from the plasmid and the LEU3 DNA from the genome, respectively. The plasmid copy number per haploid genome was estimated by comparing the relative amount of the LEU2 DNA and the LEU3 DNA as follows: Plasmid copy number $=2^{\text {(Cp_LEU2-Cp_LEU3) }}$, where Cp_LEU2 and Cp_LEU3 are the crossing points of PCR amplifications using the $L E U 2$ and $L E U 3$ primer sets, respectively.

The relative copy number change of the TEV plasmid was calculated as follows: Relative copy number change $=\left(\Delta C_{T} / C_{V}-w t C_{T} / w t C_{V}\right) /\left(w t C_{T} / w t C_{V}\right)$, where $\Delta C_{T}$ is the average copy number of the TEV plasmid in each knockout strain, $\Delta C_{V}$ is the average copy number of the empty vector plasmid in each knockout strain, $w t C_{T}$ is the average copy number of the TEV plasmid 
in the wild-type strain, and $w t C_{V}$ is the average copy number of the empty vector plasmid in the wild-type strain.

\section{Western blotting}

Cells were cultivated in SC medium, and the proteins were extracted as described previously [7]. The proteins were separated using $\mathrm{NuPAGE}^{\bullet} 4-12 \%$ Bis-Tris gels, and transferred them onto a PVDF membrane using iBlot $^{\circ}$ gel transfer system (Life Technologies), then the target proteins were detected using their specific antibodies. For the detection of GFP, TEV protease, and Cdc28, antibodies 1814460 (Roche), PAB19931 (Abnova), and sc-6709 (Santa Cruz Biotechnology) were used, respectively. For the second antibodies, Histofine ${ }^{\circ}$ simple stain MAX PO (MULTI) and Histofine ${ }^{\circ}$ simple stain MAX PO (G)(Nichirei) were used. Coomassie ${ }^{\circ}$ G-250 (SimplyBlue ${ }^{\text {mix }}$ SafeStain, Life Technologies) was used to stain loading controls.

\section{Computation}

Numerical simulations were performed using Matlab version 7.3.0 with the "stabilization model" described previously [9]. The rate of degradation of kd20 was gradually increased until the cell cycle simulation yielded the result "dead." The relative degradation rate change was calculated as follows: Relative degradation rate change $=$ $\left(\Delta U L_{k d 20}-w t U L_{k d 20}\right) / w t U L_{k d 20}$, where $\Delta U L_{k d 20}$ is the upper limit of $\mathrm{kd} 20$ in a deletion mutant model and $w t U L_{k d 20}$ is that in the wild-type model.

\section{Additional file}

Additional file 1: This file contains 3 tables (Table S1. Summary of construction of GFP-DegF integrated strains with different lengths of CDC19 promoters. Table S2. Upper limits of the rates of degradation of $\mathrm{Cdc} 20$ (kd20) in gene-deletion models. Table S3. PCR primers used in this study.) and 4 figures (Figure S1. Serial deletions of the CDC19 promoter. Figure S2. Correlation between the copy numbers of vector and TEV plasmids. Figure S3. Potential outcomes of TIPI-gTOW of Cdc20 in cell cycle regulator deletion strains and their regulatory interactions (Case 1). Figure S4. Potential outcomes of TIPI-gTOW of Cdc20 in cell cycle regulator deletion strains and their regulatory interactions (Case 2)).

\section{Competing interests}

The authors declare that they have no competing interests.

\section{Authors' contributions}

MS mainly carried out the molecular genetic experiments in this study. SS carried out the initial construction of TIPI-gTOW. KK carried out computational analysis. KM participated in the constructions of plasmids. RK performed western blotting. HM conceived of the study, and participated in its design and coordination and draft the manuscript. All authors read and approved the final manuscript.

\section{Acknowledgements}

The authors would like to thank Ayako Chino (Okayama University) for various discussions related to this study, and Dr. Christof Taxis (Philipps-Universität, Marburg, Germany) for kindly providing us with the TIPI plasmids (pDS5, pDS41). This work was supported by the Special Coordination Fund for
Promoting Science and Technology, Grants-in-Aid for Scientific Research (B). The funding agencies were not involved in study design, data collection and analysis, decision to publish, or manuscript preparation.

\section{Author details}

'Research Core for Interdisciplinary Sciences, Okayama University, Kita-ku, Okayama, Japan. ${ }^{2}$ Graduate School of Natural Science and Technology, Okayama University, Kita-ku, Okayama, Japan. ${ }^{3}$ Quantitative Biology Center, RIKEN, Suita, Osaka, JAPAN.

Received: 23 May 2013 Accepted: 27 December 2013

Published: 7 January 2014

\section{References}

1. Zaslaver A, Mayo AE, Rosenberg R, Bashkin P, Sberro H, Tsalyuk M, Surette $M G$, Alon U: Just-in-time transcription program in metabolic pathways. Nat Genet 2004, 36:486-491.

2. Dekel E, Alon U: Optimality and evolutionary tuning of the expression level of a protein. Nature 2005, 436:588-592.

3. Wagner A: Energy constraints on the evolution of gene expression. Mol Biol Evol 2005, 22:1365-1374.

4. Alon U, Surette MG, Barkai N, Leibler S: Robustness in bacterial chemotaxis. Nature 1999, 397:168-171.

5. Little JW, Shepley DP, Wert DW: Robustness of a gene regulatory circuit. EMBO J 1999, 18:4299-4307.

6. von Dassow G, Meir E, Munro EM, Odell GM: The segment polarity network is a robust developmental module. Nature 2000, 406:188-192.

7. Moriya H, Shimizu-Yoshida Y, Kitano H: In vivo robustness analysis of cell division cycle genes in Saccharomyces cerevisiae. PLoS Genet 2006, 2:e111.

8. Moriya H, Makanae K, Watanabe K, Chino A, Shimizu-Yoshida Y: Robustness analysis of cellular systems using the genetic tug-of-war method. Mol Biosyst 2012, 8:2513-2522.

9. Kaizu K, Moriya H, Kitano H: Fragilities caused by dosage imbalance in regulation of the budding yeast cell cycle. PLOS Genet 2010, 6:e1000919.

10. Moriya H, Chino A, Kapuy O, Csikász-Nagy A, Novák B: Overexpression limits of fission yeast cell-cycle regulators in vivo and in silico. Mol Syst Biol 2011, 7:556.

11. Makanae $\mathrm{K}$, Kintaka R, Makino T, Kitano H, Moriya H: Identification of dosage-sensitive genes in Saccharomyces cerevisiae using the genetic tug-of-war method. Genome Res 2013, 23:300-311.

12. Giaever G, Chu AM, Ni L, Connelly C, Riles L, Véronneau S, Dow S, Lucau-Danila A, Anderson K, André B, et al: Functional profiling of the Saccharomyces cerevisiae genome. Nature 2002, 418:387-391.

13. Costanzo M, Baryshnikova A, Bellay J, Kim Y, Spear ED, Sevier CS, Ding H, Koh JL, Toufighi K, Mostafavi S, et al: The genetic landscape of a cell. Science 2010, 327:425-431.

14. Hillenmeyer ME, Ericson E, Davis RW, Nislow C, Koller D, Giaever G: Systematic analysis of genome-wide fitness data in yeast reveals novel gene function and drug action. Genome Biol 2010, 11:R30.

15. Mnaimneh S, Davierwala AP, Haynes J, Moffat J, Peng WT, Zhang W, Yang X, Pootoolal J, Chua G, Lopez A, et al: Exploration of essential gene functions via titratable promoter alleles. Cell 2004, 118:31-44.

16. Drinnenberg IA, Weinberg DE, Xie KT, Mower JP, Wolfe KH, Fink GR, Bartel DP: RNAi in budding yeast. Science 2009, 326:544-550.

17. Breslow DK, Cameron DM, Collins SR, Schuldiner M, Stewart-Ornstein J, Newman HW, Braun S, Madhani HD, Krogan NJ, Weissman JS: A comprehensive strategy enabling high-resolution functional analysis of the yeast genome. Nat Methods 2008, 5:711-718.

18. Schuldiner M, Collins SR, Thompson NJ, Denic V, Bhamidipati A, Punna T, Ihmels J, Andrews B, Boone C, Greenblatt JF, et al: Exploration of the function and organization of the yeast early secretory pathway through an epistatic miniarray profile. Cell 2005, 123:507-519.

19. Finoux AL, Séraphin B: In vivo targeting of the yeast Pop2 deadenylase subunit to reporter transcripts induces their rapid degradation and generates new decay intermediates. J Biol Chem 2006, 281:25940-25947.

20. Kanemaki M, Sanchez-Diaz A, Gambus A, Labib K: Functional proteomic identification of DNA replication proteins by induced proteolysis in vivo. Nature 2003, 423:720-724.

21. Nishimura K, Fukagawa T, Takisawa H, Kakimoto T, Kanemaki M: An auxinbased degron system for the rapid depletion of proteins in nonplant cells. Nat Methods 2009, 6:917-922. 
22. Taxis C, Stier G, Spadaccini R, Knop M: Efficient protein depletion by genetically controlled deprotection of a dormant N-degron. Mol Syst Biol 2009, 5:267.

23. Taxis C, Knop M: TIPI: TEV protease-mediated induction of protein instability. Methods Mol Biol 2012, 832:611-626.

24. Varshavsky A: The $\mathrm{N}$-end rule pathway of protein degradation. Genes Cells 1997, 2:13-28

25. Ugolini S, Bruschi CV: The red/white colony color assay in the yeast Saccharomyces cerevisiae: epistatic growth advantage of white ade8-18, ade2 cells over red ade2 cells. Curr Genet 1996, 30:485-492.

26. Stevenson LF, Kennedy BK, Harlow E: A large-scale overexpression screen in Saccharomyces cerevisiae identifies previously uncharacterized cell cycle genes. Proc Natl Acad Sci USA 2001, 98:3946-3951.

27. Tavormina PA, Burke DJ: Cell cycle arrest in cdc20 mutants of Saccharomyces cerevisiae is independent of Ndc10p and kinetochore function but requires a subset of spindle checkpoint genes. Genetics 1998, 148:1701-1713.

28. Lin YY, Qi Y, Lu JY, Pan X, Yuan DS, Zhao Y, Bader JS, Boeke JD: A comprehensive synthetic genetic interaction network governing yeast histone acetylation and deacetylation. Genes Dev 2008, 22:2062-2074.

29. Schott EJ, Hoyt MA: Dominant alleles of Saccharomyces cerevisiae CDC20 reveal its role in promoting anaphase. Genetics 1998, 148:599-610.

30. Tsuchiya D, Gonzalez C, Lacefield S: The spindle checkpoint protein Mad2 regulates $\mathrm{APC} / \mathrm{C}$ activity during prometaphase and metaphase of meiosis I in Saccharomyces cerevisiae. Mol Biol Cell 2011, 22:2848-2861.

31. Lew DJ, Weinert T, Pringle JR: Cell cycle control in Saccharomyces cerevisiae. In The Molecular and Cellular Biology of the Yeast Saccharomyces: Cell Cycle and Cell Biology. Edited by Pringle JR, Broach JR, Jones EW. Cold Spring Harbor, NY: Cold Spring Harbor Laboratory Press; 1997:607-695.

32. Bandyopadhyay $S$, Mehta M, Kuo D, Sung MK, Chuang R, Jaehnig EJ, Bodenmiller B, Licon K, Copeland W, Shales M, et al: Rewiring of genetic networks in response to DNA damage. Science 2010, 330:1385-1389.

33. Chen KC, Calzone L, Csikasz-Nagy A, Cross FR, Novak B, Tyson JJ: Integrative analysis of cell cycle control in budding yeast. Mol Biol Cell 2004, 15:3841-3862.

34. Baryshnikova A, Costanzo M, Dixon S, Vizeacoumar FJ, Myers CL, Andrews B, Boone C: Synthetic genetic array (SGA) analysis in Saccharomyces cerevisiae and Schizosaccharomyces pombe. Methods Enzymol 2010, 470:145-179.

35. Baryshnikova A, Costanzo M, Kim Y, Ding H, Koh J, Toufighi K, Youn JY, Ou J, San Luis BJ, Bandyopadhyay S, et al: Quantitative analysis of fitness and genetic interactions in yeast on a genome scale. Nat Methods 2010, 7:1017-1024.

36. Li Z, Vizeacoumar FJ, Bahr S, Li J, Warringer J, Vizeacoumar FS, Min R, Vandersluis B, Bellay J, Devit M, et al: Systematic exploration of essential yeast gene function with temperature-sensitive mutants. Nat Biotechnol 2011, 29:361-367.

37. Deutschbauer AM, Jaramillo DF, Proctor M, Kumm J, Hillenmeyer ME, Davis RW, Nislow C, Giaever G: Mechanisms of haploinsufficiency revealed by genome-wide profiling in yeast. Genetics 2005, 169:1915-1925.

38. Springer M, Weissman JS, Kirschner MW: A general lack of compensation for gene dosage in yeast. Mol Syst Biol 2010, 6:368.

39. Brachmann CB, Davies A, Cost GJ, Caputo E, Li J, Hieter P, Boeke JD: Designer deletion strains derived from Saccharomyces cerevisiae S288C: a useful set of strains and plasmids for PCR-mediated gene disruption and other applications. Yeast 1998, 14:115-132.

40. Amberg DC, Burke D, Strathern JN: Methods in Yeast Genetics: A Cold Spring Harbor Laboratory Course Manual. New York: Cold Spring Harbor Laboratory Press; 2005.

41. Goldstein AL, McCusker JH: Three new dominant drug resistance cassettes for gene disruption in Saccharomyces cerevisiae. Yeast 1999, 15:1541-1553.

doi:10.1186/1752-0509-8-2

Cite this article as: Sasabe et al.: Evaluation of the lower protein limit in the budding yeast Saccharomyces cerevisiae using TIPI-gTOW. BMC Systems Biology 2014 8:2.

\section{Submit your next manuscript to BioMed Central and take full advantage of:}

- Convenient online submission

- Thorough peer review

- No space constraints or color figure charges

- Immediate publication on acceptance

- Inclusion in PubMed, CAS, Scopus and Google Scholar

- Research which is freely available for redistribution

Submit your manuscript at www.biomedcentral.com/submit
C Biomed Central 